\title{
INVESTIGATING THE EFFECTIVENESS OF VISUAL MATERIALS FOR TEACHING VOCABULARY AT PRIMARY LEVEL
}

\author{
Muhammad Safdar Bhatti ${ }^{1}$, Rafia Mukhtar ${ }^{2}$, Shumaila Mazhar ${ }^{3}$, Imrana Touqir ${ }^{4}$ \\ ${ }^{1}$ TEFL Coordinator, AIOU Bahawalpur, Pakistan, safdarbhatti2001@gmail.com \\ 2 Director, SAQE, Bahawalpur, Pakistan, saqe1994@gmail.com \\ ${ }^{3}$ Instructor, SAQE, Bahawalpur, Pakistan,honestfriend99@gmail.com \\ ${ }^{4}$ Assistant Deputy Commissioner, Bahawalpur, Pakistan, imrana_911@yahoo.com
}

\begin{abstract}
This article is designed to make a review of teaching methodology at primary level. The main purpose of this article is to indicate effectiveness of visual materials for teaching vocabulary at Primary level and to find out the problems faced by the teachers. A survey was conducted and analyzed with the help of qualitative research. 200 primary level teachers were chosen from District Bahawalpur. A questionnaire was provided to take teachers' views regarding the use of visual materials i.e. (pictures and charts) that provides the teachers a full opportunity to rely on the application of direct method of teaching. This article is a gate way for English Teachers in general and primary teachers in particular to achieve their mainly focused goals and suggestions for the solution of problems faced by them and the taught. Researchers' conclusion with suggestions and recommendations was also summed up at the end of the study.
\end{abstract}

Keywords: English, vocabulary, pictures, charts, visual materials

\section{INTRODUCTION}

English has become part and parcel of our culture and its vocabulary is very vast. There is limited time for the teacher to complete the described course. A large number of students in the class is also a big hurdle in learning process. The unknown words used in books make it boring and monotonous. This makes the learner divert his attention from work. That's why the importance of vocabulary cannot be neglected at any stage whether the students are learning speaking, reading or writing skills. They are constantly in touch with vocabulary and vocabulary is important in shaping students' perception.

As A.G Jimson says that all languages are spoken and begin with ears. To speak any language, a person must know $100 \%$ phonetics, $90 \%$ its grammar and $10 \%$ vocabulary. So the importance of vocabulary for making teaching and learning process interesting cannot be over looked. Because it is a "stock of words" used in a language.

At this time the use of visual materials i.e. pictures and charts plays a vital role for teaching vocabulary at any level. In fact pictures and charts are the natural source and human beings have been relying on them since their creation. Pictures are the realistic representation of the objects represented and provide the realistic 
basis for teaching vocabulary. Pahuja (1995) says that vocabulary is the list of words that plays an important role in teaching learning process. At the same time Majid (2000) suggested that the spirit for learning can be achieved by the use of pictures and charts in teaching vocabulary.

Many people have worked in vocabulary development. As mentioned by Burg (1998) in vocabulary building, the problem is not much finding new words, even finding out what they mean, the problem is to remember, then to fix them permanently in the learner's mind. This quality of vocabulary can be achieved only by using visual materials in the class room. Majid (2000) argued that different visual materials are used in teaching vocabulary. So the main focus of this study was remained on teaching vocabulary with the help of visual materials.

\section{BACKGROUND of THE STUDY}

Teaching English vocabulary to students has always been a problem for teachers. In Pakistani classrooms, no importance is given to this aspect. Students are told to learn English vocabulary by heart. There is still no authentic way to teach vocabulary to Government students. Majid (2000) commented that the primary teachers can play very important role to affect literacy rate in every country of the world. Primary School teachers always lay the foundations of a nation in this respect. That's why the primary teachers have to be well versed with the latest methods and techniques. They are not only imparting knowledge but also grooming the young children in such a way that they can become responsible citizens of tomorrow. Mughal (2002) thought out well that the primary teachers are the main source for the students from whom they acquire knowledge and skills. So, they should have necessary qualities for teaching English because English is taught as compulsory subject in all Government institutions but during the class work there is limited time for the teachers to complete the described course. The unknown words used in the book make it boring and monotonous. At this time the use of visual materials plays a vital role for teaching vocabulary at primary level. In fact visual materials are the natural source and human beings have been relying on them since their creation. Pictures are the realistic representation of the objects being presented and provide the realistic basis for teaching vocabulary. The importance of vocabulary cannot be neglected at any stage because it is soul and essence of a language.

\section{SIGNIFICANCE of THE STUDY}

This study is significant to make the teacher familiar to use the visual materials for teaching vocabulary and make students' performance better. This study helps the teachers to know how they can teach English vocabulary effectively by using visual materials. It is also beneficial for the students as they learn a large number of the items through visual materials. It also facilitates course designers to include certain activities concerning vocabulary in the prescribed syllabus which provide sufficient grounds to all the experiences of the learners as visual materials sensitively and specifically express the real objects.

This study helps the students in focusing their attention, stimulating their interest, giving them real impact, making them aware, modernizing their learning and acquisition. This work also draws the attention of teachers to use visual materials (pictures and charts) in their teaching.

\section{OBJECTIVES of THE STUDY}

This study is based on these objectives:

1. To find out the role of visual materials in retaining vocabulary for language by the learners.

2. To find out the factors which effect teaching vocabulary through visual materials.

3. To highlight the role of visual materials in teaching learning situation to facilitate the learner to use vocabulary in his real life situation more confidently.

4. To find out methods and techniques which enhance teachers' expertise while using visual materials for vocabulary development of the students.

\section{STATEMENT of THE PROBLEM}

This research will highlight the importance of visual materials for teaching vocabulary at primary level. This study will also draw the attention of the teachers to use visual materials to make their teaching effective, easy and interesting. This research is conducted in order to find out the effectiveness of visual materials (pictures and charts) for teaching vocabulary at primary level.

\section{DELIMITATION}

The present study was held at Govt. Primary Schools for Boys of Bahawalpur district. Only 200 English 
teachers were selected randomly. Only teaching English through visual materials were focused.

\section{REVIEW OF RELATED LITERATURE}

As grammar is the backbone of a language, vocabulary is the soul and essence of a language. Allen (1983) defined vocabulary in the following way:

- All the words of a language.

- The sum of words used for understanding or command of a particular group of persons.

A learner when comes to know what a word means can use other words in the place of that particular word to convey the sense concerned.

\section{Kinds of Vocabulary}

Verges (1990) divided vocabulary into two kinds:

I. Active vocabulary or production vocabulary.

II. Passive vocabulary or recognition vocabulary.

\section{Active Vocabulary}

There are some words which are correctly used by language users in their speech and writing. These are common and familiar words (Verges, 1990).

\section{Passive Vocabulary}

Verges (1990) defines that there are some words which are in print or in speech that seem unfamiliar. The learner has to recognize these words.

Majid (2000) argued that the importance of vocabulary cannot be neglected at any stage, whether the students are learning speaking, reading or writing skills. They are constantly in touch with vocabulary and vocabulary is important in shaping one's perception. Thoughts and perception become fully conscious which must be formulated in words. Without words no one can either understand or retain any sort of material. Haq (1994) considers English a rich language having more than five Lac words and says that it is impossible for the teacher to teach all these words even in the years which are devoted to its study.

Tylor (1990) commented that teaching vocabulary is very important factor at primary level. It is a fact that the knowledge which is gained by the learner at early stage is permanent and everlasting. So, the students must be given a good knowledge of vocabulary. Robinett (1988) also supports the idea of Pahuja (1995) and gives importance to teach vocabulary items as they carry cultural information. Wright (2005) suggested the way the speakers of a language view their experience has a bearing on the way in which they categorize ideas and certain problems may develop in learning system because of the pre-disposition of the speakers of a language to categorize the meaning in particular way in their first language. The pre- disposition tends to be carried out into the second language.

As stated by Max Well Nurn Berg (1961) teaching vocabulary is a difficult and time consuming task. Whether time is devoted to this task, complete mastery over all the words is possible neither by the teacher nor by the students. It is necessary for the teacher to adopt some easy approaches for teaching vocabulary and the limited range of words during the specific period. As teachers are the pivots of educational structure/system. So they should have the package of qualities.

Haq (1994) widely recognized that audio- visual materials mean the devices which can be used in teaching for their appeal to the ear and the eye. (Bajwa 2003) supported this fact by reporting that the learners need assistance for understanding at every stage of lesson. This assistance is given two ways. Firstly, suitable examples should be given. Secondly, by using the audio- visual materials these examples increase the effectiveness of learning because they help the learners to understand the idea more clearly. They make the classroom activities more meaningful and interesting.

Haq (1994) narrates the following rules that govern the selection of words:

\section{- Words Frequency}

It means the number of times a particular word is used in normal reading matter. The more a word is used the more it becomes familiar. 


\section{- Words Usefulness}

Words usefulness depends upon how for it is suited to the mental level of the learners.

\section{- Words Structured Value}

Words are graded on the basis of their functions. Content words stand for a thing, action and quality. Structural words join sentences, phrases and clauses.

\section{- Words Range of Applicability}

This means in how many situations a certain word can be used.

\section{- Words Productivity}

It means words power for word building by means of prefixes and suffixes.

\section{RESEARCH METHODOLOGY}

The present study is survey based. A questionnaire was prepared to take views of the teachers regarding the use of visual materials for teaching English vocabulary. Data were collected from $\mathbf{2 0 0}$ teachers who were randomly selected from $\mathbf{1 0 0}$ Primary schools and described in a qualitative manner. To express the teachers' views regarding the present topic, qualitative research is the most suitable.

\section{RESEARCH PARTICIPANTS}

The researchers personally visited the selected Govt. Primary schools for the purpose of data collection. A structured questionnaire was distributed among 200 teachers who were chosen randomly. They were teaching English at primary level. Questionnaire was given to those teachers. They solved questionnaires and returned to the researchers.

\section{RESEARCH TOOL}

Questionnaire has been considered as an appropriate survey tool for collecting required information by many researchers. So the researchers also had selected questionnaire as their survey tool. They devised a questionnaire after a careful study of the instruments available on the relevant studies.

\section{QUESTIONNAIRE}

A questionnaire was made. It was based on 10 questions. First 4 questions were close-ended while other six were open-ended. As to get brief views related to the use of visual materials to teach vocabulary, openended questions were more appropriate. They were personally handed over to the participants and then analyzed in a qualitative manner.

\section{DATA ANALYSIS and DISCUSSION}

The current paper was aimed to evaluate the "Effectiveness of Visual Materials (Pictures and Charts) for teaching Vocabulary at Primary Level". The study was materialized by devising a questionnaire.

The pictures which the teachers should bring into the classroom for vocabulary teaching should be limited in number, selected intelligently and relevant to the objectives of the lesson, grade and level of the students.

Teachers expressed that students should be told before which part of the picture is the target area and what role it is going to play in the target activity because it makes clearer the use of pictures for teaching vocabulary. Teachers should point out important features and parts of the target picture. They should also point out and explain focal points.

The importance of pictures, photographs, drawings, pictures from magazines and newspapers cannot be denied. So they can be used for teaching new vocabulary items at low cost.

Describing the teaching of synonyms, teachers told that they should find simple synonyms for the target words or to give short and simple definition. For example the teacher can say "bold" means "brave" or a generous man is a man who likes giving away things to other people. But a teacher must be careful to present ambiguous synonyms and definitions. For example, he should not give "to arrive" as a synonyms of "turn up."

For teaching vocabulary at primary level, teachers should give words opposite in meaning against the target items. A teacher should take care not to present contrasts and opposites which create ambiguity.

Now talking about the importance of vocabulary teaching through visual material teachers expressed that 
charts should be hung where they can be well lighted. The letters should be large and bold enough to avoid strain on eyes. The teacher should ensure that his pupils have the necessary background to understand the charts that are being displayed.

It is also the duty of the teacher to make sure that the students should at least be able to use vocabulary with correct form and appropriate level of formality.

At primary level, students learn vocabulary very easily if it is associated with pictures for which it stands. The teacher should show the students various pictures/charts of classroom objects like table, chair, book, bag and out of the classroom like flowers, trees, fruits, leaves as he names these objects. In this way students can enhance their vocabulary and will be able to add more and more words according to the target picture.

\section{CONCLUSION}

The problem of learning difficult words which are faced by the students whether they are learning listening, speaking, reading or writing skills seriously affects the students' learning speed and quality. So, visual materials (pictures, charts) are really very helpful in this regard. They are not only helpful in remembering the vocabulary but also well enough to clear students' concepts regarding new things. Therefore, difficult words should be taught through visual materials by allocating class time regularly.

\section{RECOMMENDATIONS}

A proper time must be allocated for teaching English vocabulary through visual materials. Always take help from the things which are near to the classroom. A proper schedule for teaching vocabulary makes students' base strong.

\section{REFERENCE LIST}

Allen, V.F., (1983), Teaching in Teaching Vocabulary.

Bajwa, M.S., (1999) Teaching of English.

Bhatti, M. S.,(2010) Noor English Grammar and Composition.

Bhalla, C. L.,(1963) Audio Visual Aids, National Defence Academy, Khadavaria Poona

Dhand, H., (1990) Techniques of Teaching, Punjabi Bagh, New Delhi.

Eisen, E., (1947) Maps Globes and Charts in American school and university American Publishing. P197.

Haq, M.S., (1989) An Approach to the Teaching of English.

Hellen, M. Carpenter., (1964) Developing Pictures Reading Skills the Instructor September.

Hill, J. W.,(1968) Audio Visual Materials and their Natural Use $4^{\text {th }}$ Edition.

Majid, S.,(2000) The Effect of Pre-School Education on language Comprehension of Children. Unpublished M. P.hil Thesis Teacher Education Department, AIOU, Islamabad.

Mughal, N. H.,(2000) A study to Examine the Competencies of Teachers for Teaching English. Unpublished M.A Education Thesis, Teacher Education Department, AIOU, Islamabad.

Pahuja, N P., (1995) Teaching of English Annual Publishers Private Limited New Delhi.

Peter, Hubbard, (1986) Training Course for TEFL Oxford University Press London. P.132

Research Methodology (2009) Allied Material for M.A TEFL AIOU, Islamabad

Taylor, L.,(1990) Teaching and Learning Vocabulary.

Varshney, L. R., (2007).

Wright, A., (1970) Visual Materials for Language Teaching.

Wright, T., (2005) How to be a Brilliant English Teacher. 